\title{
Colon or Rectum Neuroendocrine Tumor pTX TNM Finding v7
}

National Cancer Institute

\section{Source}

National Cancer Institute. Colon or Rectum Neuroendocrine Tumor PTX TNM Finding v7. NCl Thesaurus. Code C90099.

Colon or rectum neuroendocrine tumor in which the primary tumor cannot be assessed. (from AJCC 7th Ed.) 